\title{
Evaluation of Brown Coloured Cotton Genotypes by Genetic Studies (Gossypium hirsutum L.)
}

\author{
G. Geetha Devi ${ }^{1 *}$, J. M. Nidagundi ${ }^{1}$, J. R. Diwan ${ }^{1}$, \\ K. Mahanthashivyogayya ${ }^{1}$ and S. G. Hanchinal ${ }^{2}$ \\ ${ }^{1}$ Department of Genetics and Plant Breeding, University of Agricultural Sciences, \\ Raichur-584104, Karnataka \\ ${ }^{2}$ Department of Entomology, University of Agricultural Sciences, \\ Raichur - 584 104, Karnataka \\ *Corresponding author
}

\section{A B S T R A C T}

\section{Keywords}

Genetic variability, Heritability, GCV, PCV, Genetic advance,

Correlation and Seed cotton yield

\section{Article Info}

Accepted:

12 September 2020 Available Online:

10 October 2020
The present study was conducted on genetic variability, correlation coefficient analysis for seed cotton yield and its component traits in 18 brown coloured cotton genotypes collected from CICR, Nagpur, which was carried out during kharif2018 at the Main Agricultural Research Station, UAS, Raichur, Karnataka. Observations on traits viz., plant height at harvest, number of sympodia, number of monopodia, sympodial length at ground level, sympodial length at $50 \%$ plant height, number of bolls per plant, lint index, boll weight, internodal distance, seed index, seed cotton yield per plant, ginning out turn, fibre length, fibre strength and micronaire were recorded. The results showed that highest GCV for number of monopoodia per plant and sympodial length at 50\% plant height. Highest heritability was observed for number of sympodia, plant height, fibre length ginning out turn and seed index. Plant height at harvest, number of monopodia per plant, number of sympodia per plant, sympodial length at ground level, intermodal distance were positively correlated with seed cotton yield and the traits viz., seed index and fibre length exhibited negative correlation.

\section{Introduction}

Cotton (Gossypium hirsutum L.) referred as "White gold" is a premier cash and fibre crop cotton, the world's most important non-food agricultural commodity used for textile purpose, is an important commercial crop grown all over the world which is mainly grown for its fibre. It is a soft, staple fibre that grows around the seed of cotton plant and some writers fabricated stories of lamb sitting inside the fruit. The lint colour of cotton under commercial cultivation is often white. In the cultivated species, brown and green colours are most common. Some of the genotypes in germplasm collection of USA 
and Russian Republics are reported to have coloured lint with shades of pink, red, blue, green and also black. In recent years coloured cottons are receiving increasing importance in view of their eco-friendly character. The awareness about the toxicity and pollution caused by synthetic dyes have revived the interest in cultivation of organic cotton. The urge for eco-friendly cotton can only be fulfilled preferably by organically grown coloured cotton, dispensing harmful chemicals in dying and processing. The estimated total area under naturally coloured cotton is around 200 acres with a total production of 330 quintals. With the modernization of spinning industry and quality conscious consumers, there is an increased emphasis on the production of superior quality of cotton. Development of cotton varieties and hybrids having greater yield potential with acceptable fibre characteristics is the main objective of cotton breeders. Seed cotton yield, its components and fibre quality characters of a plant are heritable in nature and thus genetic improvement in all these characters through selection and breeding is possible. Correlation coefficient analysis measures the magnitude of relationship between various plant characters and determines the component character on which selection can be based for improvement in seed cotton yield and fibre quality. Hence, the present investigation was carried out to find the variability, heritability and nature of correlation among various characters, influence on seed cotton yield of Gossypium hirsutum L.

\section{Materials and Methods}

During kharif2018-2019, 18 hirsutum coloured cotton genotypes along with two checks SCS-793, BGDS-1063 were raised in the field at Main Agricultural Research Station, Raichur, Karnataka in augmented design with a spacing of $75 \times 30 \mathrm{~cm}$. Five plants were taken at random in each entry and data recorded on plant height at harvest, number of sympodia, number of monopodia, sympodial length at ground level, sympodial length at $50 \%$ plant height, number of bolls per plant, lint index, boll weight, internodal distance, seed index, ginning out turn, fibre length, fibre strength and micronaire. Observations of the above traits were recorded in each genotype and subjected to a statistical analysis by using windostat. The data was analysed for variability, heritability, genotypic component of variation, genetic advance and correlation.

\section{Results and Discussion}

In the table-1, highest GCV and PCV was recorded for number of monopodia per plant $(54.31 \%)$, sympodial length at $50 \%$ plant height $(30.82 \%)$ and moderate for number of bolls per plant $(17.66 \%)$ similar was reported from (Ali et al., 2010), lowest was observed for boll weight, fibre quality parameters, lint index and seed index it reveals a lowest genetic base for all the above mentioned traits. Heritability showed highest for number of sympodia $(98.65 \%)$, sympodial length at $50 \%$ plant height $(99.99 \%)$, seed cotton yield per plant $(96.33 \%)$ and fibre length $(91.88 \%)$. Heritability estimate is important because genotypic coefficient of variation doesn't give the idea of total variation heritable. Heritability and genetic advance estimation give an idea about relative amount of heritability and give an idea about the effectiveness with which selection can be practiced for genetic improvement of a particular character based on phenotypic performance. High heritability coupled with high genetic advance observed for plat height, sympodial length at ground level and seed cotton yield per plant. Genetic advance ranged from 0.4003 to 32.41 for the traits viz., lint index and plant height respectively. 
Table.1 Estimation of variability parameters for yield, yield attributing and fibre quality traits in colour Cotton (Gossypium hirsutum L.) genotypes

\begin{tabular}{|c|c|c|c|c|c|c|c|c|c|}
\hline \multirow[t]{2}{*}{ Sl. NO. } & \multirow[t]{2}{*}{ Character } & \multirow[t]{2}{*}{ Mean } & \multicolumn{2}{|c|}{ Range } & \multicolumn{2}{|c|}{ Coefficient Variation } & \multirow[t]{2}{*}{$\mathbf{h}^{2}(\%)$} & \multirow{2}{*}{$\begin{array}{c}\text { GA } \\
(\%)\end{array}$} & \multirow{2}{*}{$\begin{array}{c}\text { GAM } \\
(\%)\end{array}$} \\
\hline & & & Minimum & $\underset{\mathrm{m}}{\text { Maximu }}$ & $\operatorname{GCV}(\%)$ & $\mathrm{PCV}(\%)$ & & & \\
\hline 1 & Plant height $(\mathrm{cm})$ & 83.55 & 45.7 & 115.7 & 19.939 & 21.113 & 89.19 & 32.41 & 38.79 \\
\hline 2 & Number of monopodia per plant & 1.09 & 0.0 & 2.7 & 54.31 & 73.99 & 53.88 & 0.8988 & 82.12 \\
\hline 3 & Number of sympodia per plant & 11.03 & 5.7 & 16.8 & 19.37 & 19.50 & 98.65 & 4.37 & 39.64 \\
\hline 4 & Sym length at ground level $(\mathrm{cm})$ & 22.07 & 10 & 32.3 & 23.66 & 27.29 & 75.21 & 9.33 & 42.28 \\
\hline 5 & Sym length at $50 \%$ plant height $(\mathrm{cm})$ & 14.77 & 5.0 & 22.3 & 30.823 & 30.825 & 99.99 & 9.38 & 63.49 \\
\hline 6 & Inter nodal distance $(\mathrm{cm})$ & 4.58 & 3.0 & 6.0 & 13.36 & 15.39 & 75.38 & 1.09 & 23.89 \\
\hline 7 & Number of bolls/plant & 14.52 & 4.0 & 25 & 17.66 & 33.58 & 27.67 & 2.78 & 19.14 \\
\hline 8 & Boll weight $(\mathrm{g})$ & 2.96 & 2.4 & 3.8 & 4.2 & 12.79 & 11.11 & 0.0869 & 2.9287 \\
\hline 9 & Upper Half Mean Length (mm) & 27.46 & 26.1 & 29.5 & 4.03 & 4.206 & 91.88 & 2.18 & 7.96 \\
\hline 10 & Fibre strength $(\mathrm{g} / \mathrm{tex})$ & 23.03 & 21.7 & 24.6 & 4.06 & 5.863 & 49.44 & 1.34 & 5.82 \\
\hline 11 & Micronaire ( $\mu \mathrm{g} / \mathrm{inch})$ & 4.22 & 3.7 & 4.9 & 8.325 & 9.578 & 75.55 & 0.6294 & 14.90 \\
\hline 12 & Ginning outturn (\%) & 32.22 & 26.7 & 36.3 & 8.409 & 8.422 & 99.7 & 5.57 & 17.29 \\
\hline 13 & Seed index $(\mathrm{g})$ & 8.82 & 8.2 & 10.1 & 6.052 & 7.681 & 81.24 & 1.47 & 19.43 \\
\hline 14 & Lint index & 4.23 & 3.0 & 5.8 & 8.74 & 16.65 & 27.56 & 0.4003 & 9.45 \\
\hline 15 & Seed cotton yield per plant $(\mathrm{g})$ & 41.1 & 19 & 60 & 24.92 & 25.39 & 96.33 & 20.71 & 50.39 \\
\hline
\end{tabular}


Table.2 Phenotypic correlation among 15 yield, yield attributing and fibre quality traits in colour cotton genotypes

\begin{tabular}{|c|c|c|c|c|c|c|c|c|c|c|c|c|c|c|c|}
\hline & $\mathbf{P H}$ & NM & NS & SLG & SLFPH & IND & NOB & BW & GOT & SI & LI & FL & MIC & FS & Y/PL \\
\hline PH & 1.00 & $0.62 * *$ & -0.08 & 0.15 & 0.15 & 0.45 & 0.52 & 0.02 & 0.18 & -0.26 & -0.02 & -0.37 & 0.10 & 0.32 & 0.3909 \\
\hline NM & & 1.00 & -0.07 & -0.19 & -0.32 & -0.24 & 0.11 & 0.32 & 0.04 & 0.13 & 0.09 & 0.06 & 0.24 & 0.02 & 0.2386 \\
\hline NS & & & 1.00 & 0.31 & 0.04 & -0.007 & 0.40 & -0.05 & 0.01 & 0.14 & 0.06 & 0.46 & 0.19 & -0.10 & 0.2913 \\
\hline SLG & & & & 1.00 & $0.88 * * *$ & $0.70^{* *}$ & $0.72 * * *$ & -0.09 & -0.14 & -0.24 & -0.24 & -0.39 & 0.26 & $0.58 *$ & 0.052 \\
\hline SLFPH & & & & & 1.00 & $0.78 * * *$ & $0.58 *$ & -0.05 & 0.01 & -0.21 & -0.10 & -0.41 & -0.00 & $0.56^{*}$ & -0.0254 \\
\hline IND & & & & & & 1.00 & $0.59 * *$ & -0.15 & 0.02 & $-0.55^{*}$ & -0.28 & $-0.63 * *$ & 0.10 & $0.69 * *$ & 0.0571 \\
\hline NOB & & & & & & & 1.00 & -0.03 & 0.17 & 0.27 & -0.04 & -0.33 & 0.17 & 0.47 & 0.2556 \\
\hline BW & & & & & & & & 1.00 & 0.05 & 0.11 & 0.08 & -0.14 & -0.14 & -0.13 & 0.4245 \\
\hline GOT & & & & & & & & & 1.00 & 0.15 & $0.82 * * *$ & 0.14 & -0.02 & -0.08 & -0.0069 \\
\hline SI & & & & & & & & & & 1.00 & $0.67 * *$ & $0.56^{*}$ & 0.03 & -0.33 & -0.0996 \\
\hline LI & & & & & & & & & & & 1.00 & 0.41 & 0.03 & -0.24 & -0.1171 \\
\hline FL & & & & & & & & & & & & 1.00 & 0.02 & $-0.56^{*}$ & -0.0834 \\
\hline MIC & & & & & & & & & & & & & 1.00 & 0.24 & -0.1668 \\
\hline FS & & & & & & & & & & & & & & 1.00 & 0.0423 \\
\hline
\end{tabular}

* Significant at 5\% $(\mathrm{p}=0.05) \quad * *$ Significant at $1 \%(\mathrm{p}=0.01)$

PH- Plant height $(\mathrm{cm}) \quad$ NM- Number of monopodia NS- Number of sympodia SLG- Sympodial length at ground level (cm)

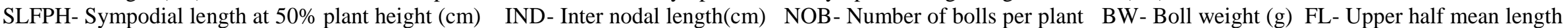

$(\mathrm{mm}) \quad$ FS- Fibre strength (g/tex) MIC- Micronaire ( $\mu \mathrm{g} / \mathrm{inch})$ GOT- Ginning outturn $(\%)$

SI- Seed index (g) LI- Lint index (g) Y/PL- Seed cotton yield per plant (g) 

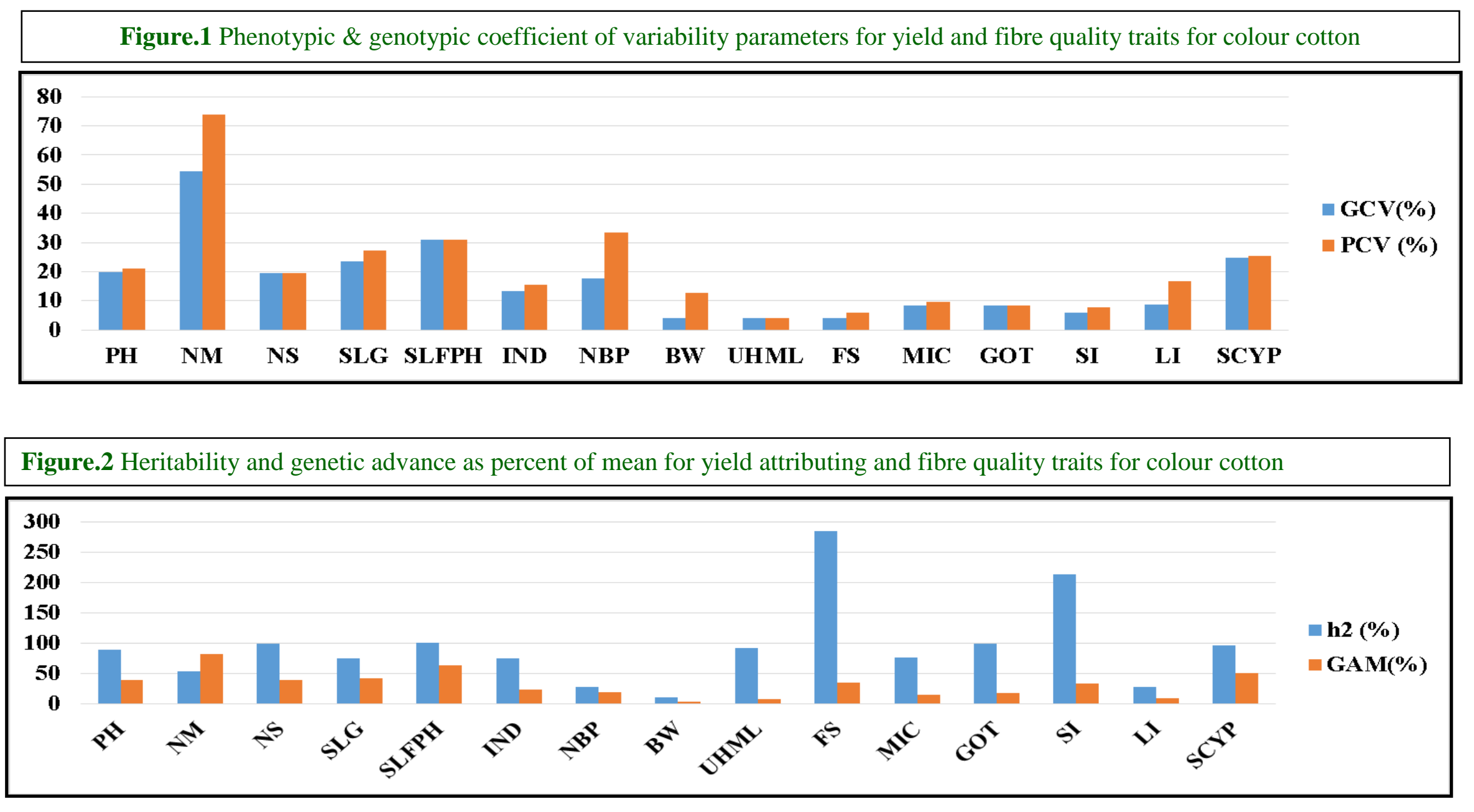

PH- Plant height $(\mathrm{cm}), \quad$ NM- Number of monopodia per plant NS- Number of sympodia per plant, SLG- Sympodial length at ground level $(\mathrm{cm})$ SLFPH- Sympodial length at 50\% plant height $(\mathrm{cm})$ IND- Inter nodal distance $(\mathrm{cm}) \quad$ NBP- Number of bolls/plant, BW- Boll weight $(\mathrm{g})$, UHML- Upper Half Mean Length (mm), FS- Fibre strength $(\mathrm{g} / \mathrm{tex}) \quad$ MIC- Micronaire ( $\mu \mathrm{g} / \mathrm{inch}), \quad$ GOT- Ginning outturn (\%)

SI- Seed index $(\mathrm{g}), \quad$ LI- Lint index, $\quad$ SCYP-Seed cotton yield per plant $(\mathrm{g})$ 
Int.J.Curr.Microbiol.App.Sci (2020) 9(10): 1405-1412

Figure.3 fs - fibre strength (g/tex)y/pl - yield per plant (g)

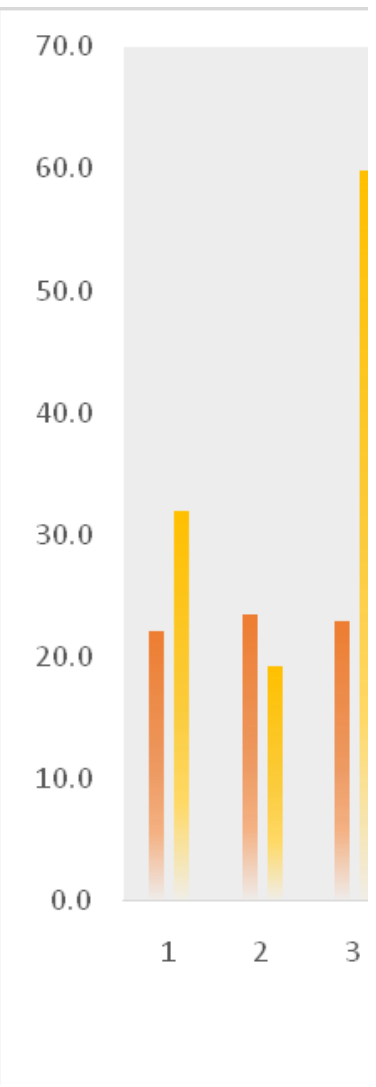


In the fig-1 highest GCV and PCV was recorded for number of monopodia per plant (54.31\%), sympodial length at $50 \%$ plant height $(30.82 \%)$ and the trait seed cotton yield per plant shown there is no difference between the GCV \& PCV, this given an anticipated result to next generations. In fig-2 heritability shown highest for number of sympodia (98.65\%), sympodial length at $50 \%$ plant height $(99.99 \%)$, seed cotton yield per plant $(96.33 \%)$ and fibre length (91.88\%). Fibre length and seed cotton yield per plant were important in the breeding of a cotton plant both in the terms of qualitative and quantitative manner. Genetic advance percent mean ranged from fibre strength to number of monopodia are $5.82 \%$ and $82.12 \%$ respectively. Fibre strength is low in colour cotton in comparison with white cotton genotypes and to indulge this trait in colour cotton is an important breeding aspect in colour cotton breeding. Even-though it shown higher heritability $(49.44 \%)$ but its genetic advance is very less (1.34\%). In the table-2, positive correlation was observed by plant height, number of monopodia (Ranjan et al., 2014) number of sympodia, intermodal distance, boll weight and bolls per plant on yield and positively correlated with seed cotton yield (Khan et al., 2009). Among all the traits, boll weight (0.4245), plant height (0.3909) and number of sympodia (0.2913) shown highest positive correlation towards yield improvement. Fibre strength (0.0423) contribution towards yield component was very less. Lint index (-0.1171) shown highest negative correlation and traits viz., sympodial length at $50 \%$ plant height, ginning out turn (Shao et al., 2016), seed index, fibre length and micronaire similar finding was reported by (Pujer et al., 2014). Plant height significantly correlated with number of monopodia and its contribution towards yield is also higher, simultaneous improvement of both of these traits to rise the yield and similar results are reported from (Abbas et al., 2013).
Positive correlations among independent variables to the dependent variable it bring light to improve cotton yield and quality. In the fig-3, out of 18 brown coloured genotypes genotypes viz., 10 and 11 shown highest fibre strength $24.4 \mathrm{~g} / \mathrm{tex}, 24.6 \mathrm{~g} / \mathrm{tex}$ respectively. Genotypes like 2, 8, 9 and 16 shown more than $23.0 \mathrm{~g} / \mathrm{tex}$. Even-though genotype -2 shown lesser yield but it possess higher fibre strength compared to the other high yielders. Coloured cotton genotypes are normally soft in texture and they possess lesser fibre strength, selection of 10 and 11 genotypes to next generation gives promising results towards the fibre strength and it is one of the most important qualitative trait in the cotton breeding.

\section{References}

Abbas, H. G., Mahmood, A. and Ali, Q., 2013, Genetic variability, heritability, genetic advance and correlation studies in cotton (Gossypium hirsutum L.). Int. Res. J. Microb, 4(6): 156-161.

Ali, M. A., Khan, I. A. and Nawab, N. N., 2010. Estimation of Genetic Divergence and Linkage for Fiber Quality Traits in Upland Cotton. J. Agric. Res, 47:229236.

Khan, N.U., Marwat, K.B., Hassan, G., Kumbhar, M.B., Farhatullah, S.Z., Khan, N., Parveen, A. and Aiman, U., 2009, Study of fiber quality traits in upland cotton using additive dominance model. Pak J Bot., 41(3): 1271-1283.

Pujer, S., Siwach, S. S., Deshmukh, J., Sangwan, R, S. and Sangwan, O., 2014, Genetic variability, correlation and path analysis in upland cotton (Gossypium hirsutumL.). Electron. J. Plant. Breed., 5(2): 284-289.

Ranjan, R., Sangwan, R.S., Siwach, S.S., Sangwan, O. and Sah, M.K., 2014. Correlation and path analysis studies in Gossypium arboreum L. Journal of 
Cotton Research and Development, 28(1), pp.37-39.

Shao, D., Wang, T., Zhang, H., Zhu, J. and Tang, F., 2016, Variation, heritability and association of yield, fibre and morphological traits in a near long staple upland cotton population. Pak. J. Bot., 48(5): 1945-1949.

\section{How to cite this article:}

Geetha Devi, G., J. M. Nidagundi, J. R. Diwan, K. Mahanthashivyogayya and Hanchinal, S. G. 2020. Evaluation of Brown Coloured Cotton Genotypes by Genetic Studies (Gossypium hirsutum L.). Int.J.Curr.Microbiol.App.Sci. 9(10): 1405-1412.

doi: https://doi.org/10.20546/ijcmas.2020.910.167 